\title{
CHEMICAL REACTION EFFECT ON UNSTEADY MHD FLOW PAST AN INFINITE VERTICAL POROUS PLATE IN THE PRESENCE OF HEAT ABSORPTION
}

\author{
G. Sreedhar \\ Research Scholar, Department of Mathematics, Rayalaseema University, Kurnool, A.P., India \\ B. Rama Bhupal Reddy \\ Professor, Department of Mathematics, K.S.R.M. College of Engineering (Autonomous), \\ Kadapa-516003, A.P., India
}

\begin{abstract}
In this paper the problem of two dimensional, unsteady, laminar, magneto hydro dynamic free convective flow through a porous medium past a vertical plate in the presence of heat absorption and chemical reaction is considered. The Dufour effect is taken into account. The free stream velocity is supposed to follow the exponentially increasing small perturbation law. The non-dimensional governing equations are solved analytically by two-term harmonic and non-harmonic functions. The velocity, temperature and concentration distributions are analyzed for different values of parameters.
\end{abstract}

Key words: MHD, Dufour effect, unsteady, heat absorption, chemical reaction.

Cite this Article: G. Sreedhar and B. Rama Bhupal Reddy, Chemical Reaction Effect on Unsteady MHD Flow Past an Infinite Vertical Porous Plate in the Presence of Heat Absorption. International Journal of Advanced Research in Engineering and Technology, 10(1), 2019, pp 95-103.

http://iaeme.com/Home/issue/IJARET?Volume=10\&Issue $=1$

\section{INTRODUCTION}

Transport phenomenon involving the combined influence of thermal and concentration buoyancy are often encountered in many engineering systems and natural environments. There are many applications of such transport processes in the industry notably in chemical distilleries, heat exchanges, solar energy collectors and thermal protection systems. In all such classes of flows, the driving force is provided by a combination of thermal and chemical diffusion effects. In atmospheric flows thermal convection of the earth by sunlight is affected by differences in water vapour concentration.

Simultaneous heat and mass transfer flow through porous medium has many engineeering and physical applications such as drying of porous solids, geothermal resorvoirs, enriched oil revovery, thermal insulation, and cooling of nuclear reactors. In the presence or absence of a 
porous medium, the combined thermal convection past a semi-infinite vertical plate has been studied by many authors $[19,13,16,7]$. Chamkha [4] developed a mathematical model governing boundary layer flow past an inclined plate embedded in a porous medium with non-uniform transverse magnetic field.

In view of magnetic field effects on the boundary layer flow, there has been a revived interest in examining magneto hydrodynamic and heat transfer flow in porous and non-porous media. Further, this kind of flow has attracted many investigators because its applications in many engineering problems for example plasma studies, nuclear reactors, MHD generators, geothermal energy extractions. Raptis [20] examined the effects of Grashof number and permeability parameter on the velocity field for steady hydro magnetic free convective flow of a conducting fluid through a porous medium bounded between two parallel plates.Bian et al. [3] has studied an electromagnetic field effect on natural convection in an porous inclined surface. An unsteady two dimensional MHD free concvetion flow in an inclined square enclosure filled with a fluid saturated porous medium is studied numerically by Khanafer and Chamkha [9]. Kim [10] have reported the effect of an electro magnetic field on unsteady twodimensional laminar flow past a semi-infinite vertical porous moving plate with constant velocity in the direction of fluid flow. Chamkha [05] have presented heat absorption effect and concentration buoyancy on unsteady MHD bounadary layer flow of a viscous, incompressible electrically conducting fluid along a semi-infinite vertical permeable moving plate. Ahmmed and Sarker [1] analyzed magneto hydrodynamic natural convection flow of fluid past a vertical plate with temperature dependent viscosity. Manjulatha et al. [12] focused on aligned magnetic field effect of free convective steady flow of a viscous, incompressible and electrically conducting fluid past an infinite vertical porous plate with heat source and radiation absorption.

Mass transfer is one of the usually encountered occurrences in chemical industries as well as in physical and biological sciences. When fluid is at rest, mass transfer takes place; the mass is transferred purely by molecular diffusion resulting from concentration gradients. For small concentration of the mass in the fluid and small mass transfer rates, the convective heat and mass transfer process are similar in nature. A number of investigations have already been carried out with combined heat and mass transfer under the assumption of different physical situations. In many chemical engineering processes, there does occur, the chemical reaction between a foreign mass and the fluid in which the plate is at rest. These processes take place in numerous industrial applications, namely, polymer production, manufacturing of ceramics or glassware and food procession.

Mohammed Ibrahim [14] studied numerically a problem of two dimensional unsteady MHD flow past a vertical porous plate with porous medium and chemical reaction. Jagadish Prakash et al. [8] investigated heat and mass transfer characteristics of unsteady heat absorbing fluid flow in an vertical wavy plate under the influence of chemical reaction and thermal radiation. Mythreye et al. [15] investigated the heat absorption and chemical reaction effects on unsteady MHD free convective flow past a semi-infinite vertical moving plate embedded in a porous medium. Ramaprasad et al. [18] have studied the free convective heat and mass trasnfer flow past an inclined moving surface of an electrically conducting, viscous, incompressible fluid in the presence of magnetic field. Guriviredddy et al., [06] investigated chemical reaction and soret effect on unsteady free convective flow past a moving porous plate in the presence of thermal radiaiton and pressure gradient. Kumaresan and Vijaya Kumar [11] examined the unsteady magneto hydrodynamic chemically reacting viscoelastic fluid flow past a vertical plate with thermal radiation and uniform temperature. Very recently, Rajkumar et al. [17] studied viscous dissipation effects on MHD laminar flow past a semi-infinite vertical porous plate with heat generation and chemical reaction. Balakrihsna et al., [2] analyzed the effects of 
chemical reaction, thermal radiation and heat absorption on casson fluid flow past an infinite inclined surface embedded in a porous medium.

\section{MATHEMATICAL FORMULATION}

We consider unsteady two-dimensional flow of laminar, incompressible, viscous, electrically conducting and heat absorbing fluid past a semi infinite vertical plate embedded in a uniform porous medium and subjected to a uniform transverse magnetic field with heat absorption and chemical reaction effect.The transverse applied magnetic field and magnetic Reynolds number are assumed to be very small so that the induced magnetic field and the hall effect are negligible. The flow is assumed to be in the $\mathrm{x}$-direction and y-axis normal to it. A magnetic field of uniform strength $B$ is introduced normal to the direction of the flow. the free stream velocity follows the exponentially increasing small perturbation law. In addition, it is assumed that the temperature and the concentration at the wall as well as the suction velocity are exponentially varying with time. The governing equations for this investigation are based on the balances of mass, linear momentum, energy and concentration species.

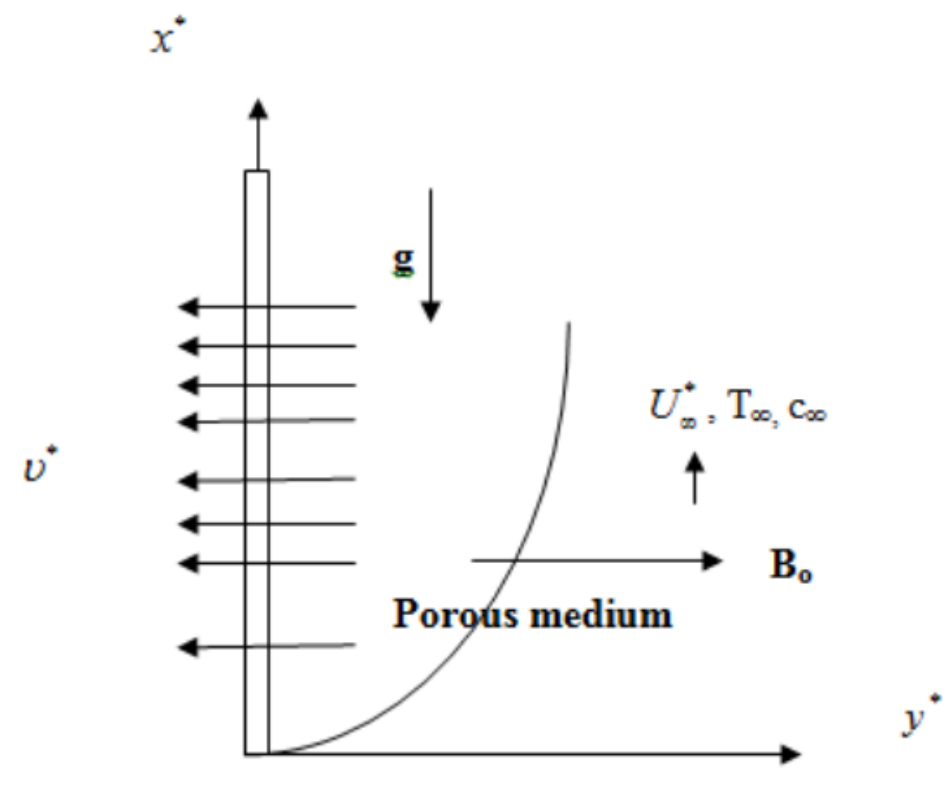

\section{Physical Model}

Taking into consideration the assumptions made above, thegoverning equations can be written in cartesian frame as follows:

$$
\begin{aligned}
& \frac{\partial v^{*}}{\partial y^{*}}=0 \\
& \frac{\partial u^{*}}{\partial t^{*}}+v^{*} \frac{\partial u^{*}}{\partial y^{*}}=-\frac{1}{\rho} \frac{\partial p^{*}}{\partial x^{*}}+v \frac{\partial^{2} u^{*}}{\partial y^{2}}+g \beta_{T}\left(T-T_{\infty}\right)+g \beta_{c}\left(c-c_{\infty}\right)-v \frac{u^{*}}{K^{*}}-\frac{\sigma}{\rho} B_{0}^{2} u^{*} \\
& \frac{\partial T}{\partial t^{*}}+v^{*} \frac{\partial T}{\partial y^{*}}=\alpha \frac{\partial^{2} T}{\partial y^{* 2}}-\frac{Q_{0}}{\rho c_{p}}\left(T-T_{\infty}\right)+\frac{D K_{T}}{c_{s} c_{p}} \frac{\partial^{2} c}{\partial y^{* 2}} \\
& \frac{\partial c}{\partial t^{*}}+v^{*} \frac{\partial c}{\partial y^{*}}=D \frac{\partial^{2} c}{\partial y^{* 2}}-D_{1}\left(c-c_{\infty}\right)
\end{aligned}
$$


The magnetic and viscous dissipations are neglected in this study. The third and fourth terms on the RHS of the momentum equation (2) denote the thermal and concentration buoyancy effects, respectively. The second and last terms of the energy equation (3) reperesents the heat absorption and diffusion thermo effects.Also, the second term in the equation (4) represents chemical reaction effect. are

The apporpriate boundary conditions for the velocity, temperature and concentration fields

$$
\begin{aligned}
& u^{*}=0, \quad T=T_{w}+\varepsilon\left(T_{w}-T_{\infty}\right) e^{n^{*} t^{*}}, c=c_{w}+\varepsilon\left(c_{w}-c_{\infty}\right) e^{n^{*} t^{*}} \text { at } y^{*}=0 \\
& u^{*} \rightarrow U_{\infty}^{*}=U_{0}\left(1+\varepsilon e^{n^{*} t^{*}}\right), T \rightarrow T_{\infty}, \quad c \rightarrow c_{\infty} \text { as } y^{*} \rightarrow \infty
\end{aligned}
$$

It is clear from equation (1) that the suction velocity at the plate surface is a function of time only. Assuming that it takes the following exponential form:

$$
v^{*}=-V_{0}\left(1+\varepsilon A e^{n^{*} t^{*}}\right)
$$

where $\mathrm{A}$ is a real positive constant, $\varepsilon$ and $\varepsilon \mathrm{A}$ are small less than unity, and $\mathrm{V}_{0}$ is a scale suction velocity which has non-zero positive constant. Outside the boundary layer, equation (2) gives

$$
-\frac{1}{\rho} \frac{\partial p^{*}}{\partial x^{*}}=\frac{\partial U_{\infty}^{*}}{\partial t^{*}}+\frac{v}{K^{*}} U_{\infty}^{*}+\frac{\sigma}{\rho} B_{0}^{2} U_{\infty}^{*}
$$

It is convenient to employ the following dimensionless variables:

$u=\frac{u^{*}}{U_{0}}, \quad v=\frac{v^{*}}{V_{0}}, \quad y=\frac{V_{0} y^{*}}{v}, \quad U_{\infty}=\frac{U_{\infty}^{*}}{U_{0}}, \quad U_{p}=\frac{u_{p}^{*}}{U_{0}}, \quad t=\frac{t^{*} V_{0}^{2}}{v}$,

$\theta=\frac{T-T_{\infty}}{T_{w}-T_{\infty}}, \quad \phi=\frac{c-c_{\infty}}{c_{w}-c_{\infty}}, \quad n=\frac{n^{*} v}{V_{0}^{2}}, \quad K=\frac{K^{*} V_{0}^{2}}{v^{2}}, \quad \operatorname{Pr}=\frac{v \rho c_{p}}{k}=\frac{v}{\alpha}$,

$S c=\frac{v}{D}, \quad M=\frac{\sigma \nu B_{0}^{2}}{\rho V_{0}^{2}}, \quad G r=\frac{v \beta_{T} g\left(T_{w}-T_{\infty}\right)}{U_{0} V_{0}^{2}}, \quad G m=\frac{v \beta_{c} g\left(c_{w}-c_{\infty}\right)}{U_{0} V_{0}^{2}}$,

$Q=\frac{v Q_{0}}{\rho c_{p} V_{0}^{2}}, \quad D u=\frac{D K_{T}}{v c_{s} c_{p}} \frac{\left(c_{w}-c_{\infty}\right)}{\left(T_{w}-T_{\infty}\right)}, \quad K r=\frac{D_{1} v}{V_{0}^{2}}$

In view of equations (7)-(9), equations (2)-(4) reduce to the following dimensionless form:

$$
\begin{aligned}
& \frac{\partial u}{\partial t}-\left(1+\varepsilon A e^{n t}\right) \frac{\partial u}{\partial y}=\frac{\partial U_{\infty}}{\partial t}+\frac{\partial^{2} u}{\partial y^{2}}+G r \theta+G m \phi+N\left(U_{\infty}-u\right) \\
& \frac{\partial \theta}{\partial t}-\left(1+\varepsilon A e^{n t}\right) \frac{\partial \theta}{\partial y}=\frac{1}{\operatorname{Pr}} \frac{\partial^{2} \theta}{\partial y^{2}}-Q \theta+D u \frac{\partial^{2} \phi}{\partial y^{2}} \\
& \frac{\partial \phi}{\partial t}-\left(1+\varepsilon A e^{n t}\right) \frac{\partial \phi}{\partial y}=\frac{1}{S c} \frac{\partial^{2} \phi}{\partial y^{2}}-K r \phi
\end{aligned}
$$

where $N=\left(M+\frac{1}{K}\right)$ and $G r, G m, P r, Q, D u, S c$ and $K r$ are the thermal Grashof number, solutal Grashof number, Prandtl number, heat absorption coefficient, dufour number, Schmidt number and chemical reaction parameter.

The dimensionless form of the boundary conditions (5) and (6) become 


$$
\begin{aligned}
& u=0, \quad \theta=1+\mathfrak{x}^{n t}, \quad \phi=1+\mathfrak{x}^{n t} \quad \text { at } \quad y=0 \\
& u \rightarrow U_{\infty}, \quad \theta \rightarrow 0, \quad \phi \rightarrow 0 \quad \text { as } \quad y \rightarrow \infty
\end{aligned}
$$

\section{SOLUTION}

Equations (10) - (12) represent a set of partial differential equations that cannot be solved in closed form. However, it can be reduced to a set of ordinary differential equations in dimensionless form that can be solved analytically. This can be done by representing the velocity, temperature and concentration as

$$
\begin{aligned}
& u=u_{0}(y)+\varepsilon e^{n t} u_{1}(y)+O\left(\varepsilon^{2}\right)+\Lambda \\
& \theta=\theta_{0}(y)+\varepsilon e^{n t} \theta_{1}(y)+O\left(\varepsilon^{2}\right)+\Lambda \\
& \phi=h_{0}(y)+\varepsilon e^{n t} h_{1}(y)+O\left(\varepsilon^{2}\right)+\Lambda
\end{aligned}
$$

Substituting equation (15) in equations (10) - (12), equating the harmonic and nonharmonic terms, and neglecting the higher-order terms of $\mathrm{O}\left(\varepsilon^{2}\right)$, we obtain the following pairs of equations for $\left(u_{0}, \theta_{0}, h_{0}\right)$ and $\left(u_{1}, \theta_{1}, h_{1}\right)$.

$$
\begin{aligned}
& u_{0}^{\prime \prime}+u_{0}^{\prime}-N u_{0}=-G r \theta_{0}-G m h_{0}-N \\
& u_{1}^{\prime \prime}+u_{1}^{\prime}-(N+n) u_{1}=-A u_{0}^{\prime}-n-N-G r \theta_{1}-G m h_{1} \\
& \theta_{0}^{\prime \prime}+\operatorname{Pr} \theta_{0}^{\prime}-Q \operatorname{Pr} \theta_{0}=-\operatorname{Pr} D u h_{0}^{\prime \prime} \\
& \theta_{1}^{\prime \prime}+\operatorname{Pr} \theta_{1}^{\prime}-(n+Q) \operatorname{Pr} \theta_{1}=-\operatorname{Pr} A \theta_{0}^{\prime}-\operatorname{Pr} D u h_{1}^{\prime \prime} \\
& h_{0}^{\prime \prime}+S c h_{0}^{\prime}-K r S c h_{0}=0 \\
& h_{1}^{\prime \prime}+S c h_{1}^{\prime}-S c(n+K r) h_{1}=-S c A h_{0}^{\prime}
\end{aligned}
$$

Where a prime denotes ordinary differentiation with respect to y.

The corresponding boundary conditions can be written as

$$
\begin{aligned}
& u_{0}=0, \quad u_{1}=0, \quad \theta_{0}=1, \quad \theta_{1}=1, \quad h_{0}=1, \quad h_{1}=1 \quad \text { at } y=0 \\
& u_{0}=1, \quad u_{1}=1, \quad \theta_{0} \rightarrow 0, \quad \theta_{1} \rightarrow 0, \quad h_{0} \rightarrow 0, \quad h_{1} \rightarrow 0 \quad \text { as } y \rightarrow \infty
\end{aligned}
$$

Solutions of equations (16) - (21) subject to equation (22) can shown to be

$$
\begin{aligned}
& u_{0}=1+C_{9} e^{-m_{1} y}+C_{10} e^{-m_{3} y}+C_{11} e^{-m_{5} y} \\
& u_{1}=C_{12} e^{-m_{1} y}+C_{13} e^{-m_{2} y}+C_{14} e^{-m_{3} y}+C_{15} e^{-m_{4} y}+C_{16} e^{-m_{5} y}+C_{17} e^{-m_{6} y}+1 \\
& \theta_{0}=C_{3} e^{-m_{1} y}+C_{4} e^{-m_{3} y} \\
& \theta_{1}=C_{5} e^{-m_{1} y}+C_{6} e^{-m_{2} y}+C_{7} e^{-m_{3} y}+C_{8} e^{-m_{4} y} \\
& h_{0}=e^{-m_{1} y}
\end{aligned}
$$


$h_{1}=C_{1} e^{-m_{1} y}+C_{2} e^{-m_{2} y}$

\section{RESULTS AND DISCUSSION}

Numerical evaluation of the analytical results reported in the previous section was performed and a representative set of results is reported graphically in Figures 1-4. These results are obtained to illustrate the influence of the heat absorption coefficient $Q$, Schmidt number Sc, Dufour number $D u$, Magnetic field parameter M, Prandtl number Pr, Permeability parameter k, the thermal Grashof number Gr, solutal Grashof number $\mathrm{Gm}$ and chemical reaction parameter $K r$. The value of Schmidt number $\mathrm{Sc}$ is taken for water-vapour $(\mathrm{Sc}=0.60)$ and Prandtl number for air $(\mathrm{Pr}=0.71)$. Throughout the calculations physical variables $\mathrm{Gr}=2$ and $\mathrm{Gm}=2$ are taken which correspond to a cooling problem.

In Figure 1, the effect of Prandtl number and increasing the magnetic field strength on the momentum boundary-layer thickness are illustrated. It is noticed that velocity of the fluid decreases with an increase of $\mathrm{Pr}$ and M. It is a well-established fact that the magnetic field presents a damping effect on the velocity field by creating a drag force that opposes the fluid motion, causing the velocity to decrease. Figure 2 illustrates the influences of the Prandtl number Pr and Schmidt number Sc on the temperature profiles respectively. It is seen that the increase in the Prandtl number leads to fall in the temperature of the fluid. The reason is that lower Pr value has more uniform temperature distribution across the thermal boundary layer as compared to higher Pr value. This phenomenon occurs when the lesser values of Prandtl number are equivalent to increasing thermal conductivity. Therefore, heat is capable to diffuse away from the heated surface more quickly compare to bigger values of Prandtl number. Also the temperature of the fluid is increased with Schmidt number.Figure 3 shows the effects of heat absorption coefficient Q, Dufour number $\mathrm{Du}$ and chemical reaction parameter $\mathrm{Kr}$ on the temperature profiles respectively. It is observed that the temperature decreases as the heat absorption coefficient Q and Dufour number Du increases whereas the temperature increases with increase of chemical reaction parameter Kr. Figure 4 shows the effects of Schmidt number $\mathrm{Sc}$ and chemical reaction parameter $\mathrm{Kr}$ on concentration profile. It is noticed that an increase in $\mathrm{Sc}$ or $\mathrm{Kr}$ decreases in concentration of the fluid.

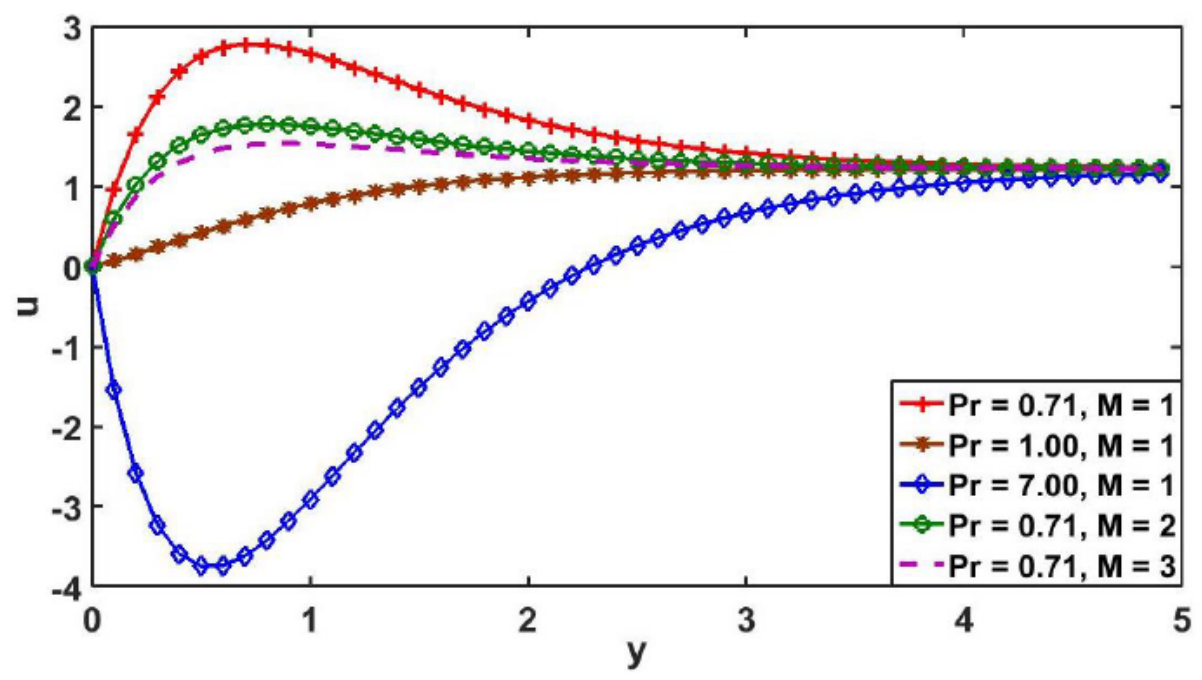

Figure 1 Effects of $\operatorname{Pr}$ and $\mathrm{M}$ on velocity profiles when $\mathrm{A}=0.5, \mathrm{k}=0.5, \mathrm{n}=0.1, \mathrm{t}=1.0, \varepsilon=0.2, \mathrm{Du}=$ $1.0, Q=1.0, \mathrm{Kr}=1.0$. 
G. Sreedhar and B. Rama Bhupal Reddy

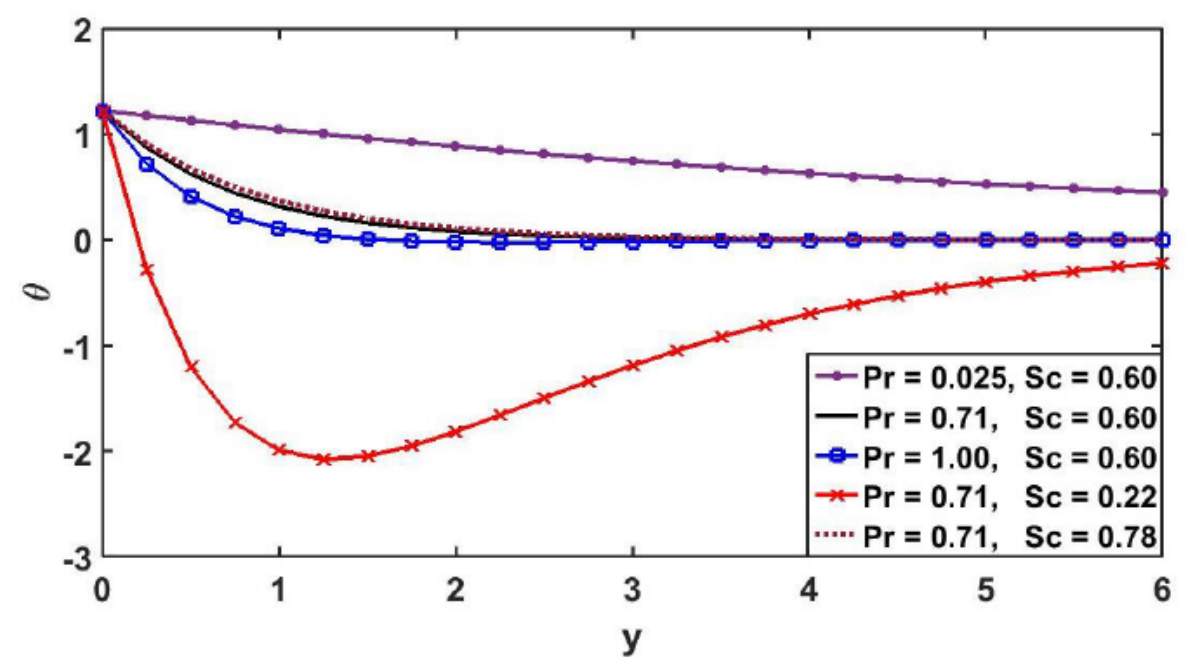

Figure 2 Effects of $\mathrm{Pr}$ and $\mathrm{Sc}$ on temperature profiles when $\mathrm{A}=0.5, \mathrm{k}=0.5, \mathrm{M}=1.0, \mathrm{n}=0.1, \mathrm{Kr}=$ $1.0, \mathrm{t}=1.0, \varepsilon=0.2, Q=1.0, \mathrm{Du}=1.0$.

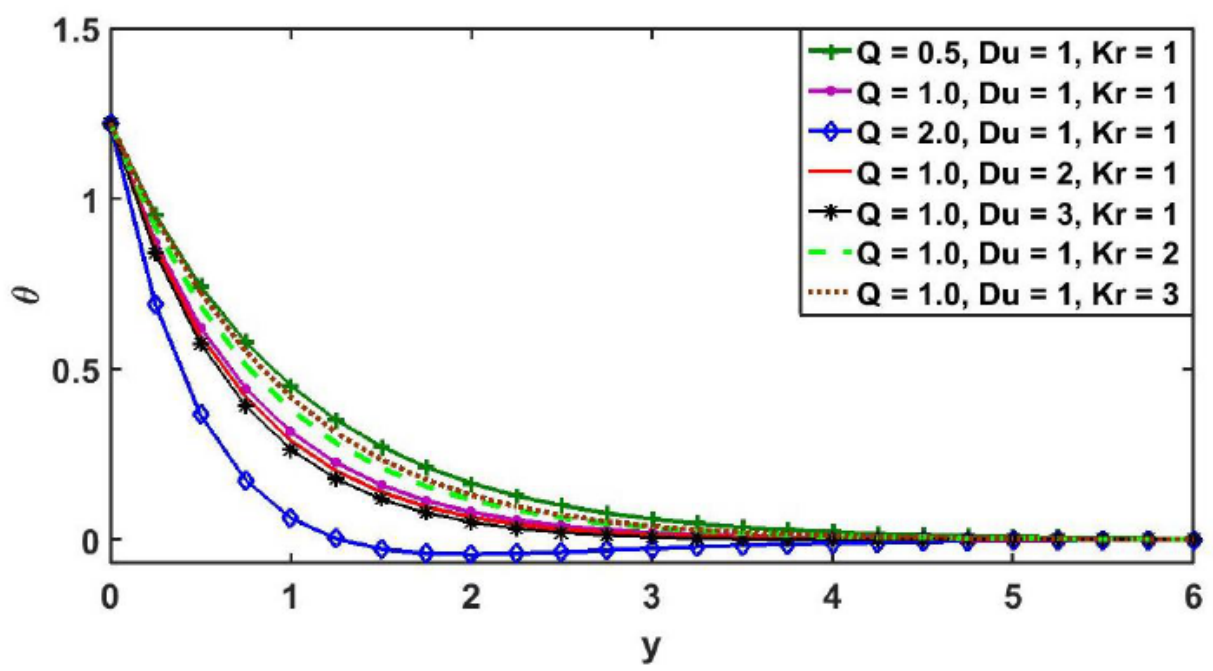

Figure 3 Effects of $Q, D u, K r o n$ temperature profiles when $\mathrm{A}=0.5, \mathrm{n}=0.1, \operatorname{Pr}=0.71, \mathrm{t}=1.0, \mathrm{M}=$ $1.0, \varepsilon=0.2$.

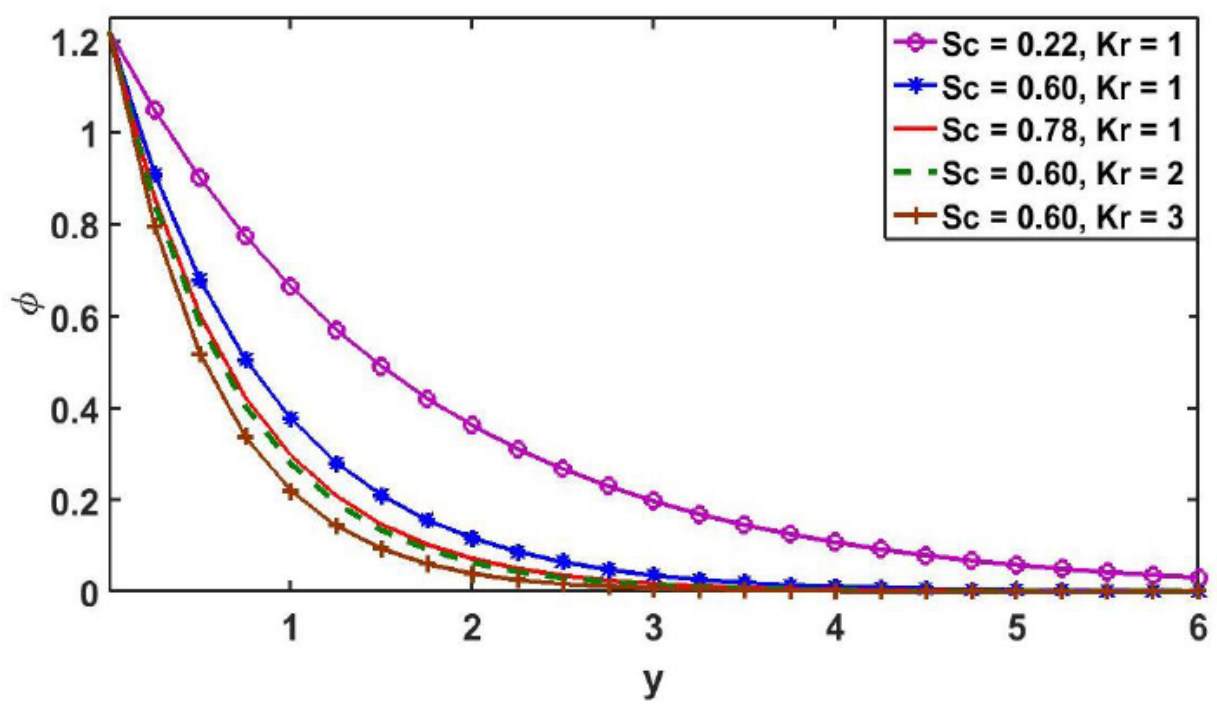

Figure 4 Effects of Scand $\mathrm{Kr}$ on concentration profiles when $\mathrm{A}=0.5, \mathrm{n}=0.1, \mathrm{t}=1.0, \varepsilon=0.2$. 


\section{CONCLUSIONS}

The governing equations for unsteady MHD convective heat and mass transfer flow past a semiinfinite vertical plate embedded ina porous medium with heat absorption and chemical reaction effectwas formulated. The flow was subjected to a transverse magnetic field. A perturbation technique is employed to solve the resulting coupled partial equations. It is observed that an increase in Prandtl number or magnetic parameter leads to reduction in the velocity field. An increase in the Prandtl number or heat absorption coefficient or Dufour number is observed to lead to decrease in temperature boundary layer while increase in the Schmidt number or chemical reaction parameter results in an increase in the temperature boundary layer. Concentration of the fluid decreases with the increase of Schmidt number or chemical reaction parameter.

\section{REFERENCES}

[1] Ahmmed, S.F. and Sarker, M.S.A., MHD natural convection flowof fluid from a vertical flat plate considering temperature dependent viscosity, Journal of Scientific Research, 2(3), 453463, 2010.

[2] Balakrishna, S., Rama Mohan, S., Viswanatha Reddy, G., and Varma, S.V.K. Effects of chemical reaction on unsteady MHD casson fluid flow past a moving infinite inclined plate through porous medium, International Journal of Engineering Science and Computing, 8(7), 18658-18666, 2018.

[3] Bian, W., Vasseur, P., Bilgen, E., and Meng, F., Effect of an eletromagnetic field on natural convection in an inclined porous layer, International Journal of Heat and Fluid Flow, 17(1), 3644, 1996.

[4] Chamkha, Ali.J. Hydromagnetic natural convection from an isothermal inclined surface adjacent to a thermally stratified porous medium, International Journal of Engineering Science, 35(10-11), 975-986, 1997.

[5] Chamkha, Ali J., Unsteady MHD convective heat and mass transfer past a semi-infinite vertical permeable moving plate with heat absorption, International Journal of Engineering Science, 42, 217-230, 2004.

[6] Gurivireddy, P., Raju, M.C., Mamatha, B., and Varma, S.V.K., Thermal diffusion effect on MHD heat and mass transfer flow past a semi infinite moving vertical porous plate with heat generation and chemical reaction, Applied Mathematics, 7, 638-649, 2016.

[7] Hsieh, J.C., Chen, T.S., and Armaly, B.F., Non similarity solutions for mixed convection from vertical surfaces in porous media variable surface temperature or heat flux, International Journal of Heat and Mass Transfer, 36(6), 1485-1493, 1993.

[8] Jagdish Prakash, Bangalore Rushi Kumar and Ramachandran Sivaraj. Radiation and Dufour effects on unsteady MHD mixed convective flow in an accelerated vertival wavy plate with varying temperature and mass diffusion, Walailak Journal of Science and Technology, 11(11), 939-954, 2014.

[9] Khanafer, K.M., and Chamkha, Ali.J., Hydromagnetic natural convection from an inclined porous square enclosure with heat generation, Numerical Heat Transfer, 33(8), 891-910, 1998.

[10] Kim, Y.J., Unsteady MHD convective heat and mass transfer past a semi-inifnite vertical porous moving plate with variable suction, International Journal of Engineering Science, 38(8) 833$845,2000$.

[11] Kumaresan, E., and Vijaya Kumar A.G., An exact solution on unsteady MHD viscoelastic fluid flow past an infinite vertical plate in the presence of thermal radiation, Frontiers in Heat and Mass Transfer, 8, 1-7, 2017.

[12] Manjulatha, V., Varma, S.V.K., and Raju, V.C.C., Effects of radiation absorption and mass transfer on the free convective flow past a vertical flat plate through a porous medium in an 
aligned magnetic field, Applications and Applied Mathematics An International Journal, 9(1), 75-93, 2014.

[13] Minkowycs, W.J., Cheng, P., Chong Hyuck Chang., Mixed convection about a non isothermal cylinder and sphere in a porous medium, Numerical Heat Transfer, 8(3), 349-359, 1985.

[14] Mohammaed Ibrahim, S. Unsteady MHD convective heat and mass trasnfer past an infinite vertical plate embedded in a porous medium with radiation and chemical reaction under the inflluence of dufour and soret effects, Chemical and Process Engineering Research, 19, 25-38, 2014.

[15] Mythreye, A., Pramod, J.P., and Balamurugan, K.S., Chemical reaction on unsteady MHD convective heat and mass transfer past a semi-inifinite vertical permeable moving plate with heat absorption, Procedia Engineering, 127, 613-620, 2015.

[16] Nakayama, A., and Koyama, H., A general similarity transformation for combined free and forced convection flows with in a fluid saturated porous medium. Journal of Heat Trasnfer, 109(4), 1041-1045, 1987.

[17] Rajkumar, K.V.B., Balamurugan, K.S., and Ramana Murthy, Ch.V., Radiation absorption and viscous dissipation effects on magneto hydrodynamic free convective flow past a semi-infinite moving vertical porous plate, International Journal of Fluid Mehanics Research, 45(5), 439-458, 2018.

[18] Ramaprasad, J.L., Balamurugan, K.S., and Dharmaiah, G., Unsteady MHD convective heat and mass transfer flow past an inclined moving surface with heat absorption, JP Journal of Heat and Mass Transfer, 13(1), 33-51, 2016.

[19] Ranganathan, P., Viskanta, R., Mixed convection boundary layer flow along a vertical surface in a porous medium, Numerical Heat Transfer, 7(3), 305-317, 1984.

[20] Raptis, A., Massalas, C., and Tzivanidis, G., Hydrodynamic free convetion flow through a porous medium between two parallel plates, Physics Letters A, 90(6), 288-289, 1982.

[21] Khaled K. Jaber, Hall Current Effect on Unsteady MHD Flow Between Two Horizontal Plates with Constant Suction, International Journal of Advanced Research in Engineering and Technology (IJARET), Volume 5, Issue 1, January (2014), pp. 83-90

[22] R. Sakthikala and S. Prahala, Heat and Mass Transfer of Unsteady Mhd Flow of Kuvshinski Fluid with Heat Source/Sink and Soret Effects, International Journal of Mechanical Engineering and Technology, 9(9), 2018, pp. 1064-1077.

[23] P. T. Hemamalini and M.Shanthi, Heat and Mass Transfer on Unsteady MHD Flow In Two Non-Conducting Infinite Vertical Parallel Plates with Inclined Magnetic Field, International Journal of Mechanical Engineering and Technology (IJMET), 9(13), 2018, pp.521-536.

[24] V. Manjula and K. V. Chandra Sekhar, Unsteady MHD Casson Fluid Flow Past an Oscillating Permeable Vertical Surface with Newtonian Heating and Thermal Radiation, International Journal of Mechanical Engineering and Technology, 9(7), 2018, pp. 1068-1079 